\title{
Improvement in the detection of Cervical Spondylotic Neuropathy through a combination of shifted frequency Distribution of F-Latency (DFL)
}

\author{
M Obaidur Rahman, Ehsan Alam Chowdhury and K Siddique-e Rabbani \\ Department of Biomedical Physics \& Technology, University of Dhaka, Dhaka, Bangladesh \\ email: mobaidur@yahoo.com, rabbani@univdhaka.edu \\ Received: 11 November 2013, Accepted: 25 December 2013
}

\begin{abstract}
Our extended group in Dhaka University has shown that frequency Distribution of F-Latency (DFL) of peripheral nerve trunks may be used for the detection of Cervical Spondylotic Neuropathy (CSN). A double blind study was performed recently to ascertain the efficacy of DFL in the detection of CSN using MRI findings as the benchmark, which was performed on 62 median nerves of 31 volunteers within an age range of 20 and 80 years. In our laboratory DFL is obtained by grouping F-latency data into $2 \mathrm{~ms}$ bins and then plotting a frequency polygon. The shapes of the resulting polygons are sorted into two categories: i) single peak and ii) broad peak or multiple peaks. The first category was taken to represent normalcy while the second category was taken to represent CSN. The present work was taken up to study the effect on the polygon patterns due to shifting of the starting point of each bin by $1 \mathrm{~ms}$. Two decisions were made for each nerve regarding normalcy or CSN based on both the individual polygon patterns. Two more decisions were made based on the logic AND and logic OR operations of the above two decisions. These four individual decisions from all the nerves were then compared with MRI findings. This shows that such bin shifting and a decision based on OR logic on the two DFLs thus obtained gives the best overall efficacy compared to all the other procedures.
\end{abstract}

Keywords: Frequency Distribution of F-latency, Bin shifting, AND \& OR logical operation.

\section{INTRODUCTION}

A peripheral nerve trunk consists of thousands of nerve fibres with varying conduction velocities, which can be well described by distribution of conduction velocity (DCV). If a motor nerve is electrically stimulated, action potentials are generated within the individual nerve fibres, which travelling to the connected muscle (called orthodromic conduction) elicit a compound muscle action potential, or an Mresponse, that can be recorded using surface electrodes. From the stimulation site the action potentials also travel in the opposite direction (called antidromic conduction) to their respective cell bodies located in the spinal cord. In most of the motor nerve cells these antidromic potentials simply die down. However, a few percent of the cell bodies backfire after a short delay and send fresh action potentials down the nerve fibres to the muscle. These in effect produces a delayed compound muscle action potential called the F-response (Fox and Hitchcock 1987, Magladery and Jr 1950, Mayer and Feldman 1967, Mcleod and Wray 1966), which is very much reduced in amplitude with respect to the M-response because of the small number of fibres involved. F-latencies obtained from multiple stimulations vary in latency, size and shape because of random backfiring of the cell bodies. Recruitment of fibres for Fresponse would depend on DCV for motor fibres directly (Rabbani et al 2007). Being a random process, they hypothesised that a frequency distribution of F-latencies (DFL) from such multiple F-Latencies would be an approximate mirror image of DCV. This new neurophysiological parameter DFL obtained 
from evoked EMG responses have previously been reported to be useful in the detection of Cervical Spondylotic Neuropathy (CSN) (Alam and Rabbani 2010, Hossain et al 2011, Rabbani et al 2014).

There are usually two major causes for CSN. One is called Radiculopathy (CSN-R) in which nerve branches coming out of the spinal cord may be compressed in the narrow channels or gaps created by the vertebral bones. This compression may be caused by bony growth in the vertebra (osteophyte), or herniation of inter-vertebral disc. Either of these compressions leads to CSN, and this condition is known as radiculopathy. The other cause of CSN is Myelopathy (CSN-M) in which one side of the spinal cord is directly pressed onto, mostly by a bulging intervertebral disc. This affects nerve fibres located in the pressed region of the spinal cord.

Recently a double blind study was performed to ascertain the efficacy of DFL in the detection of CSN using MRI findings as the benchmark (Chowdhury 2013) which showed that DFL can predict CSN to a high degree of reliability.

In our laboratory DFL is obtained by grouping F-latency data into $2 \mathrm{~ms}$ bins and then plotting a frequency polygon. The resulting polygon shapes are sorted into two categories: i) single peak and ii) broad peak or multiple peaks. The first category was taken to represent normalcy while the second category was taken to represent CSN. Different types of DFL typically obtained are shown in Figure 1-4.

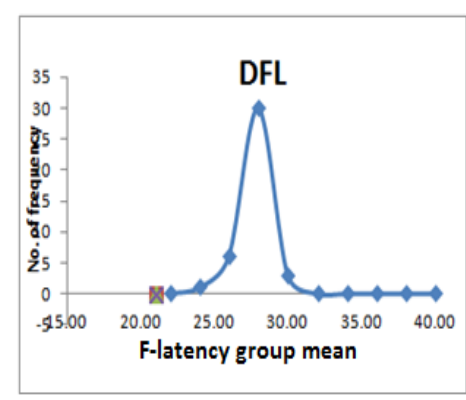

Figure 1: Single Peak
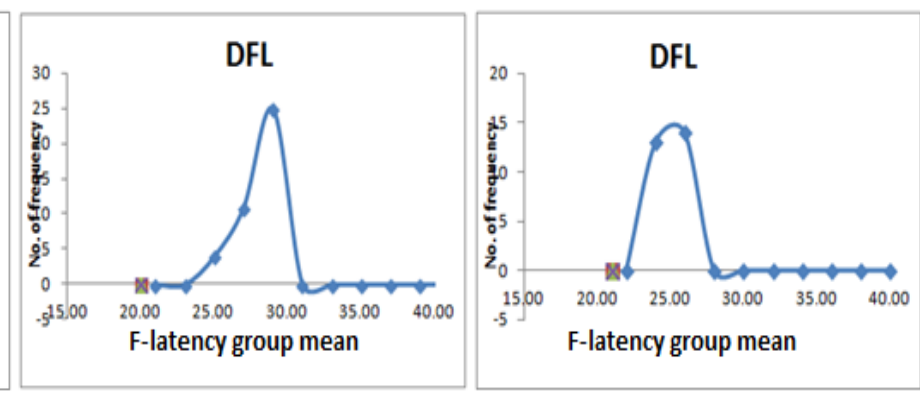

Figure 2: Broad Peak

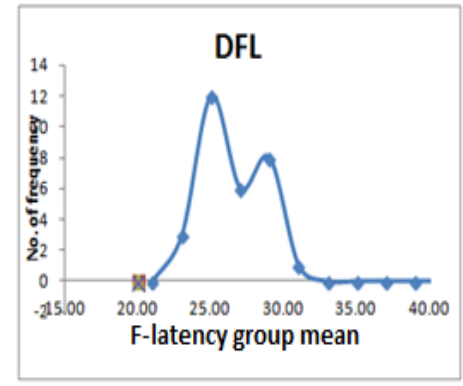

Figure 3: Double Peak

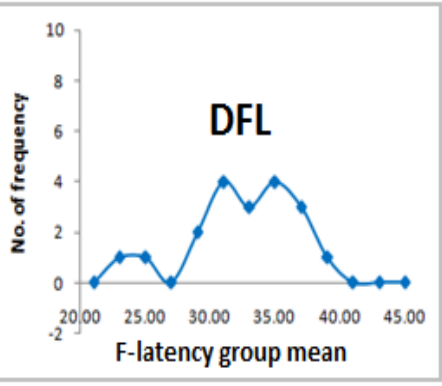

Figure 4: Triple Peak

A single peak was defined as the polygon which has a single high value (peak) while the adjacent values (at intervals of $2 \mathrm{~ms}$ ) are very small as shown in Fig.1. Double or triple peaks were also visualy determined simply, as shown in Figs, 3 and 4. The polygon shape was considered as a broad peak where non-zero and significant frequency exists at at least $4 \mathrm{~ms}$ difference (two bin separation) from the position 
of the peak, with intermediate bins having significant frequency values as well as shown in Fig.2. A recent work carried out in Singapore (Rabbani et al 2014) has helped improve the definition of a broad peak with relation to the occurrence of CSN. According to this definition, if the adjacent frequency values were greater than one third of the peak frequency (as in Fig. 3) then it would be considered a broad peak as well. Comparing figures 1, 2 and 3, it is obvious that there is a very small difference in between these shapes while it is very critical to distinguish a single peak from a broad peak for the diagnosis of CSN.

During the present work it was observed that while making the frequency polygons of DFL, if the starting point for the grouping into the $2 \mathrm{~ms}$ bins is changes by $1 \mathrm{~ms}$, then the pattern sometimes changes from a single peak to a broad peak, or from a broad peak to double peak, or vice versa. This poses a difficulty regarding the decision on the diagnosis of CSN which relies on these shapes of the DFL polygon. For this reason the present work was taken up to systematically study the effect of this shift in the starting value of the bins of earlier data and how the inferences from the slightly different patterns may be combined to get a better decision on the pattern for the diagnosis of CSN.

\section{METHODS}

The study was performed on the data obtained in an earlier study (Chowdhury 2013) which was carried out on 62 median nerves of 31 subjects with age ranging from 20yrs to 70 yrs. MRI reports indicating CSN were also available for most of the subjects. However, two nerves of two individual subjects had insufficient MRI information and these were excluded from the present study. So this study essentially included data from 56 median nerves of 29 subjects.

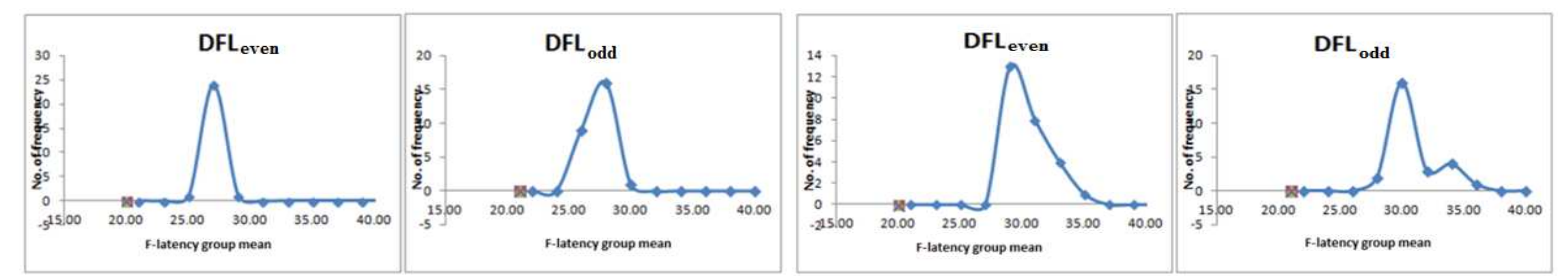

Figure 5: $\mathrm{DFL}_{\mathrm{even}}$ and $\mathrm{DFL}_{\mathrm{odd}}$ for two different subjects

Frequency distribution for a continuous variable is usually performed choosing appropriate bins or groups. All the previous work in our laboratory used a bin size of $2 \mathrm{~ms}$ to obtain a DFL polygon. Typical values of F-latency for median nerves from adult subjects vary between $20 \mathrm{~ms}$ and $35 \mathrm{~ms}$. In the previous work bin values were chosen at intervals (all in ms) $20^{+}-22,22^{+}-24, \ldots$ so on. Here the starting value is an even number and let us name the DFL thus obtained as $\mathrm{DFL}_{\text {even. }}$. We would like to see what changes in shape occurs, particularly with respect to the detection of CSN, if a $1 \mathrm{~ms}$ shift is made in the choice of the bins, i.e. if the bins were chosen at intervals (all in ms) $21^{+}-23,23^{+}-25 \ldots$ so on. Let us name the DFL thus obtained as $\mathrm{DFL}_{\text {odd. }}$. Figure 5 shows the polygon shapes for two subjects for both $\mathrm{DFL}_{\text {even }}$ and $\mathrm{DFL}_{\text {odd }}$ where the shapes change between the classifications considered for diagnosis in the present work as mentioned before.

Since the patterns change through this process of bin shifting, we were interested to see if any combination of the decisions based on these changed patterns can improve the diagnostic ability of DFL. 
We considered two approaches, one using logical OR operation and the other using logical AND operation on the decisions given by the two patterns as a result of bin shifting. These were to be compared with the decisions given by the MRI findings which have been considered as the gold standard in the previous study (Chowdhury et al 2014).

For these logical operations the diagnosis based on DFL and MRI were assigned the letters ' $\mathrm{Y}$ ' and ' $\mathrm{N}$ ' to represent the presence of CSN (yes) and absence of CSN (no) respectively. As already mentioned, if the DFL shows a single peak, we interpret this as normal, i.e. the diagnosis is a 'no' indicated by ' $\mathrm{N}$ '. If a DFL gave broad, double or triple peak, the diagnosis is a 'yes' indicated by ' $\mathrm{Y}$ '. For each nerve of a subject, these diagnoses were made with both $\mathrm{DFL}_{\text {even }}$ and $\mathrm{DFL}_{\text {odd. }}$. The MRI findings were similarly assigned ' $\mathrm{Y}$ ' or ' $\mathrm{N}$ ' values based on the findings of the radiologist which were taken from the earlier work (Chowdhury et al 2014). It needs to be mentioned that in this earlier work DFL gave a better efficacy if even mild findings of MRI were taken to represent CSN, which was also chosen for this work.

The diagnosis based on individual shapes of $\mathrm{DFL}_{\text {even }}$ and $\mathrm{DFL}_{\text {odd }}$ and the two mentioned combinations (OR and AND) were performed. These four sets of diagnosis were then compared with the MRI findings. This gave us a way to identify which of the diagnoses gave the best performance for DFL.

To determine the predictive capabilities of these four sets of diagnoses based on DFL we determined the following parameters from the relevant tables: true positives (TP), true negatives (TN), false positives (FP) and false negatives (FN). These parameters were then analysed to obtain values of correct prediction (CP) or efficacy, Sensitivity (Sen) and Specificity (Sp) defined as (all expressed in percentage):

$$
\begin{aligned}
& \mathrm{CP}=(\mathrm{TP}+\mathrm{TN}) / \text { Total number } \\
& \text { Sen }=\mathrm{TP} /(\mathrm{TP}+\mathrm{FN}) \\
& \mathrm{Sp}=\mathrm{TN} /(\mathrm{TN}+\mathrm{FP}) .
\end{aligned}
$$

The higher the value for each, the better is the performance of the new test regime, here of DFL.

\section{RESULTS AND OBSERVATIONS}

The diagnosis of CSN based on MRI findings and the bin-shifted DFLs, $\mathrm{DFL}_{\text {even }}$ and $\mathrm{DFL}_{\text {odd }}$, are presented in Table 1. The predictive capabilities for the four types of DFL for the detection of CSN is presented in table 2 .

A quick observation reveals that the $\mathrm{OR}$ combination of $\mathrm{DFL}_{\text {even }}$ and $\mathrm{DFL}_{\text {odd }}$ gives the best overall performance. 
Table 1: Comparative study between diagnoses for CSN based on MRI and DFL

\begin{tabular}{|c|c|c|c|}
\hline \multirow{2}{*}{$\begin{array}{c}\text { Subject. } \\
\text { No. }\end{array}$} & \multirow{2}{*}{$\begin{array}{c}\text { CSN } \\
\text { diagnosis } \\
\text { from MRI }\end{array}$} & \multicolumn{2}{|c|}{ CSN diagnosis from } \\
\hline & & DFL $_{\text {even }}$ & $\mathbf{D F L}_{\text {odd }}$ \\
\hline 1 & $\mathrm{Y}$ & $\mathrm{Y}$ & $\mathrm{Y}$ \\
\hline 2 & $\mathrm{Y}$ & $\mathrm{Y}$ & $\mathrm{Y}$ \\
\hline 3 & $\mathrm{Y}$ & $\mathrm{Y}$ & $\mathrm{Y}$ \\
\hline 4 & $\mathrm{Y}$ & $\mathrm{Y}$ & $\mathrm{Y}$ \\
\hline 5 & $\mathrm{Y}$ & $\mathrm{N}$ & $\mathrm{N}$ \\
\hline 6 & $\mathrm{Y}$ & $\bar{Y}$ & $\mathrm{~N}$ \\
\hline 7 & $\mathrm{Y}$ & $\mathrm{N}$ & $\mathrm{Y}$ \\
\hline 8 & $\mathrm{Y}$ & $\mathrm{Y}$ & $\mathrm{Y}$ \\
\hline 9 & $\mathrm{Y}$ & $\mathrm{Y}$ & $\mathrm{Y}$ \\
\hline 10 & $\mathrm{Y}$ & $\mathrm{Y}$ & $\mathrm{Y}$ \\
\hline 11 & $\mathrm{Y}$ & $\mathrm{Y}$ & $\mathrm{N}$ \\
\hline 12 & $\mathrm{Y}$ & $\mathrm{Y}$ & $\mathrm{Y}$ \\
\hline 13 & $\mathrm{Y}$ & $\mathrm{Y}$ & $\mathrm{Y}$ \\
\hline 14 & $\mathrm{Y}$ & $\mathrm{Y}$ & $\mathrm{Y}$ \\
\hline 15 & $\mathrm{Y}$ & $\mathrm{Y}$ & $\mathrm{Y}$ \\
\hline 16 & $\mathrm{Y}$ & $\mathrm{Y}$ & $\mathrm{Y}$ \\
\hline 17 & $\mathrm{Y}$ & $\mathrm{Y}$ & $\mathrm{N}$ \\
\hline 18 & $\mathrm{Y}$ & $\mathrm{Y}$ & $\mathrm{N}$ \\
\hline 19 & $\mathrm{Y}$ & $\mathrm{Y}$ & $\mathrm{Y}$ \\
\hline 20 & $\mathrm{Y}$ & $\mathrm{Y}$ & $\mathrm{Y}$ \\
\hline 21 & $\mathrm{Y}$ & $\mathrm{Y}$ & $\mathrm{N}$ \\
\hline 22 & $\mathrm{Y}$ & $\mathrm{Y}$ & $\mathrm{Y}$ \\
\hline 23 & $\mathrm{Y}$ & $\mathrm{Y}$ & $\mathrm{N}$ \\
\hline 24 & $\mathrm{Y}$ & $\mathrm{Y}$ & $\mathrm{N}$ \\
\hline 25 & $\mathrm{Y}$ & $\mathrm{Y}$ & $Y$ \\
\hline 26 & $\mathrm{~N}$ & $\mathrm{Y}$ & $\mathrm{N}$ \\
\hline 27 & $\mathrm{Y}$ & $Y$ & $\mathrm{Y}$ \\
\hline 28 & $Y$ & $\mathrm{~N}$ & $Y$ \\
\hline
\end{tabular}

\begin{tabular}{|c|c|c|c|}
\hline \multirow{2}{*}{$\begin{array}{c}\text { Subject. } \\
\text { No. }\end{array}$} & \multirow{2}{*}{$\begin{array}{c}\text { CSN } \\
\text { diagnosis } \\
\text { from MRI }\end{array}$} & \multicolumn{2}{|c|}{ CSN diagnosis from } \\
\hline & & DFL $_{\text {even }}$ & DFL $_{\text {odd }}$ \\
\hline 29 & $\mathrm{Y}$ & $\mathrm{Y}$ & $\mathrm{Y}$ \\
\hline 30 & $\mathrm{Y}$ & $\mathrm{Y}$ & $\mathrm{Y}$ \\
\hline 31 & $\bar{Y}$ & $\bar{Y}$ & $\bar{Y}$ \\
\hline 32 & $\mathrm{Y}$ & $\mathrm{Y}$ & $\mathrm{N}$ \\
\hline 33 & $\mathrm{Y}$ & $\mathrm{Y}$ & $\mathrm{Y}$ \\
\hline 34 & $\mathrm{Y}$ & $\mathrm{Y}$ & $\mathrm{N}$ \\
\hline 35 & $\mathrm{Y}$ & $\mathrm{Y}$ & $\mathrm{Y}$ \\
\hline 36 & $\mathrm{Y}$ & $\mathrm{N}$ & $\mathrm{Y}$ \\
\hline 37 & $\mathrm{~N}$ & $\mathrm{~N}$ & $\mathrm{Y}$ \\
\hline 38 & $\mathrm{Y}$ & $\mathrm{Y}$ & $\mathrm{Y}$ \\
\hline 39 & $\mathrm{Y}$ & $\mathrm{N}$ & $\mathrm{N}$ \\
\hline 40 & $\mathrm{Y}$ & $\mathrm{N}$ & $\mathrm{Y}$ \\
\hline 41 & $\mathrm{Y}$ & $\mathrm{N}$ & $\mathrm{N}$ \\
\hline 42 & $\mathrm{Y}$ & $\mathrm{Y}$ & $\mathrm{Y}$ \\
\hline 43 & $\mathrm{Y}$ & $\mathrm{Y}$ & $\mathrm{Y}$ \\
\hline 44 & $\mathrm{Y}$ & $\mathrm{Y}$ & $\mathrm{Y}$ \\
\hline 45 & $\mathrm{Y}$ & $\mathrm{N}$ & $\mathrm{Y}$ \\
\hline 46 & $\mathrm{Y}$ & $\mathrm{Y}$ & $\mathrm{Y}$ \\
\hline 47 & $\mathrm{Y}$ & $\mathrm{Y}$ & $\mathrm{Y}$ \\
\hline 48 & $\mathrm{Y}$ & $\mathrm{N}$ & $\mathrm{Y}$ \\
\hline 49 & $\mathrm{Y}$ & $\mathrm{Y}$ & $\mathrm{Y}$ \\
\hline 50 & $\mathrm{Y}$ & $\mathrm{N}$ & $\mathrm{N}$ \\
\hline 51 & $\mathrm{Y}$ & $\mathrm{Y}$ & $\mathrm{Y}$ \\
\hline 52 & $\mathrm{Y}$ & $\mathrm{N}$ & $\mathrm{Y}$ \\
\hline 53 & $\mathrm{~N}$ & $\mathrm{~N}$ & $\mathrm{Y}$ \\
\hline 54 & $\mathrm{~N}$ & $\mathrm{Y}$ & $\mathrm{Y}$ \\
\hline 55 & $\mathrm{Y}$ & $\mathrm{Y}$ & $\mathrm{Y}$ \\
\hline 56 & $\mathrm{Y}$ & $\mathrm{N}$ & $\mathrm{Y}$ \\
\hline
\end{tabular}


Table 2: Predictive capabilities of the four types of DFL for CSN

\begin{tabular}{|l|c|c|c|c|}
\hline & \multirow{2}{*}{ DFL $_{\text {even }}$} & \multirow{2}{*}{ DFL $_{\text {odd }}$} & \multicolumn{2}{|c|}{ Logical Operation } \\
\cline { 4 - 5 } & & & OR & AND \\
\hline True Positive (TP) & 40 & 39 & 48 & 31 \\
\hline True Negative (TN) & 2 & 1 & 0 & 3 \\
\hline False Positive (FP) & 2 & 3 & 4 & 1 \\
\hline False Negative (FN) & 12 & 13 & 4 & 21 \\
\hline Correct Prediction (CP) \% & 75 & 71 & 86 & 61 \\
\hline Sensitivity (Sen) \% & 77 & 75 & 92 & 60 \\
\hline Specificity (Sp) \% & 50 & 25 & $0^{*}$ & 75 \\
\hline
\end{tabular}

* the number of TN is ' 0 ' so the value of specificity is not useful from such a data

\section{Discussions}

The work on DFL (a statistical frequency distribution of F-latencies from multiple F-responses) is already established for CSN detection by several groups of Dhaka University and its associates in Singapore. Since DFL is used as a screening tool for CSN diagnosis depending upon the polygon shapes, choice of its pattern is important. The observation of a change in the pattern of DFL through changing of the starting point of bins while preparing the DFL led to a confusion in diagnosis initially, but has eventually helped develop the present methodology, which seems to be a significant improvement. The present work has helped improve the prediction capability of DFL significantly.

As can be seen from Table 2, the correct prediction capability (or efficacy) had the highest value of $86 \%$ for the OR combination while the nearest one was $75 \%$ using one of the individual DFL patterns $\left(\mathrm{DFL}_{\text {even }}\right)$. Similarly, the Sensitivity was very high, $92 \%$ for the OR combination while the nearest one was $77 \%$ using $\mathrm{DFL}_{\text {even }}$ pattern.

The specificity data was unreliable as there were very few true negatives in the data sets. Therefore, the assessment should be based on the other two parameters. Therefore, the present work has given an improved method for the predictive ability of DFL, establishing this new technique for the detection of CSN on a much stronger footing.

\section{Acknowledgement:}

The authors would like to acknowledge ISP of Uppsala University, Sweden, for partial funding of this project.

\section{References:}

Alam MJ \& Rabbani KS. 2010. Possible detection of cervical spondylotic neuropathy using Distribution of F-latency (DFL), a new neurophysilogical parameter. BMC Research Notes, 3.

Chowdhury EA. 2013. Study of the efficacy of the Distribution of F-latency (DFL) in the diagnosis of cervical spondylosis. M.Phil., University of Dhaka.

Chowdhury EA, Rahman MO \& Rabbani KS. 2014. Comparing DFL and MRI findings. Bangladesh Journal of Medical Physics, 6. 
Fox JE \& Hitchcock ER. 1987. F wave size as a monitor of motor neuron excitability: Effect of deafferentation. J Neurol. Neurosurg. Psychiatry, 50 453-459.

Hossain MI, Chowdhury EA, Mamun AA, Salam A, Baig TN \& Rabbani KS. 2011. Use of Distribution of F-latency (DFL) in the Detection of Cervical Spondylotic Neuropathy. Bangladesh Journal of Medical Physics, 4. 37-42.

Magladery JW \& Jr DB McDougal. 1950. Electrophysiological studies of nerve and reflex activity in normal man. Bull John Hopkins Hosp., 86. 265-290.

Mayer RF \& Feldman RG. 1967. Observations on the nature of F wave in man. Neurology, 17. 147-156.

McLeod JG \& Wray SH. 1966. An experimental study of the F wave in the baboon. J Neurol. Neurosurg. Psychiatry, 29. 196-200.

Rabbani KS, Alam MJ \& Salam A. 2007. Frequency Distribution of F-Latencies (DFL) has Physiological Significance and Gives Distribution of COnduction Velocity (DCV) of Motor Nerve Fibres With Implications for Diagnosis. J. Biol. Phys., 33. 291-303.

Rabbani KS, Yassin N \& Lo YL 2014. Identification of Cervical Spondylotic Radiculo-Myelopathy using Distribution of F-Latency (DFL), a new nerve conduction parameter. Under process. 